Commentary

\title{
Saving Lives: Mapping the Power of LGBTIQ+ First Nations Creative Artists
}

\author{
Sandy O’Sullivan
}

Department of Indigenous Studies, Macquarie University, Sydney, NSW 2109, Australia; E-Mail: sandy.osullivan@mq.ed.au

Submitted: 6 April 2021 | Accepted: 6 April 2021 | Published: 15 April 2021

\begin{abstract}
In 2020, I was funded by the Australian Research Council to undertake research that examines the ways in which queer Indigenous creative practitioners create impact and influence. With a program titled "Saving Lives: Mapping the Influence of LGBTIQ+ First Nations Creative Artists," the mapping is currently underway to explore how creativity has been used to demonstrate our reality and potential as queer First Nations' Peoples. The title of this commentary explicitly reframes this from influence, to one of insistent resistance. It explores beyond how we persuade, to understand why the resistance in the work of First Nations' queer creatives lays the groundwork for a future where the complexity of our identities are centred, and where young, queer Indigenous people can realise their own imaginings.
\end{abstract}

\section{Keywords}

Aboriginal; creative arts; First Nations; Indigenous; LGBTIQ+; queer; transgender

Issue

This commentary is part of the issue "Young, Indigenous, LGBTIQ+: Understanding and Promoting Social and Emotional Wellbeing" edited by Karen Soldatic (Western Sydney University, Australia), Linda Briskman (Western Sydney University, Australia), William Trewlynn (BlaQ Aboriginal Corporation, Australia), John Leha (BlaQ Aboriginal Corporation, Australia), Corrinne Sullivan (Western Sydney University, Australia) and Kim Spurway (Western Sydney University, Australia).

(C) 2021 by the author; licensee Cogitatio (Lisbon, Portugal). This commentary is licensed under a Creative Commons Attribution 4.0 International License (CC BY).

\section{Introduction}

As a central provocation, this commentary proposes a future for young, queer Indigenous people, and for our descendants, where the complexity of their lives is a gift, and not a burden. It explores the richness in locating the representation of what it is to be queer and Indigenous, and it reveals creative practice that explores the complexity of our queerness combined with other aspects of our identities. As provocation, it also ponders the ideas of Gomeroi theorist, Alison Whittaker's proposal that the colonial system is tested by queerness, and often found lacking in its willingness to understand the complexities of First Nations Peoples (Whittaker, 2015, p. 226). Finally, it questions the value of resistance and how, through this act, comes the centring of complex First Nations peoples' lives and a challenge to the colonial project of gender and sexuality (O'Sullivan, 2019, p. 107).

The "Saving Lives: Mapping the Influence of LGBTIQ+ First Nations Creative Artists" project is new, and aims to support a better understanding of our complexities through creative practice; but creative representation as a means to comprehend the multiplicity of who we are is as old as First Nations culture(s). Story as a measure of cultural transmission is central to Indigenous ways of being and knowing, and is informed by a deep history of connectedness and kinship (Behrendt, 2021). This measure has been reinforced by cultural imperatives to retain and share knowledge where our records were otherwise erased and dismissed through the enaction of the colonial project (Russell, 2005, p. 163). Storytelling, however, is complex and not merely a simulacrum of iterative colonial categorisation and record keeping. It is expansive, and it grows with each story and through each storyteller, helping us make sense of our world (Behrendt, 2021, p. 11; O'Sullivan, 2019, p. 111).

In this brief provocation, I will consider the ways in which expansive representation and complexity supports young, queer First Nations people. The importance of belonging is evidenced in examples of this idea of story as empowerment. In N'tacinowin inna nah: Our Coming in Stories (Wilson, 2008, p. 194), Opaskwayak 
Cree researcher Alex Wilson invokes the power of 'coming in' as an inverted and inclusive response to 'coming out.' The project gathered stories of belonging, explored community nurturing and supporting people in their entirety, as central within their community. These and other community-developed programs offer strategies for us to curate our own experiences, and to make opportunities that allow multiple and diverse voices to emerge. Young queer First Nations' people have a right to take pride of place centred in their cultures, and they have a fundamental right to the tools to imagine and deliver their own futures.

\section{Visibility: Challenging Symbolic Annihilation}

For people of colour and LGBTIQ+ people, representations on screen that are available to young people have a positive effect on their sense of self and wellbeing (Peruta \& Powers, 2017, p. 1134; Yan, 2019, p. 849). The inverse is also true: Character portrayals can reinforce stereotypes or tropes of intersecting identities (McLaughlin \& Rodriguez, 2017, p. 1197). What we do not know is the effect that the limited presence of Indigenous or queer screen-based characters-and the complete absence of intersecting queer, Indigenous characters-has had on older queer Indigenous people. There have been no studies and no mapping of where these intersecting characters were available or present, how they were perceived, or the impact they had when they became available. The "Saving Lives" project will seek to remedy this, but it will also extend to the limited-but at least present-intersectional representations available today both on screen and in broader creative spaces. In this way, "Saving Lives" frames a challenge to a symbolic annihilation that comes with a lack of representation (O'Sullivan, 2019, p. 111) by mapping the presence of queer, Indigenous creative representations and by analysing the impact these representations have on Indigenous peoples, whether queer or not.

Beyond fictional or retold characters, what role does the story from an individual tell, what impact will it have on young people for whom greater representation is available? Furthermore, what impact will the complexity of representation have on people 'coming in' to their sexuality and gender? Enter Steven Oliver (Kuku-Yalanji, Waanyi, Gangalidda, Woppaburra, Bundjalung, and Biripi) with his recent cabaret, Bigger and Blacker. He presents his story-or parts of it-as a performer instantly recognisable in Australia as a protagonist asserting his queer Blackness across the ABC TV sketch series, Black Comedy (Watego, 2021). Unlike the scripted Black Comedy, Bigger and Blacker privileges his voice, experience, influence, and his history. Chelsea Watego writes that Bigger and Blacker does not cater to a non-Indigenous audience, but instead uses inside jokes and references aimed at Aboriginal and Torres Strait Islander People (Watego, 2021). Oliver's script and performance comes from a place of being Black and queer in this continent, as he ponders the concerns of representation-in particular, the risk of stereotyping in role he is best known for. He conversely explores the risks of a lack of representation by flexing his broad experiences and coding them as gay, and Black, and his.

What is profound in Oliver's performance, is in telling his individual history, he does not continuously navigate between being gay or Black. This is framed from the outset, linguistically and specifically. In this way, with no sexuality reveal, and no reveal on what his Aboriginality means beyond his own experience, the audience is told a more complex storying of his life, his queerness, andseparately and in complexity-his Blackness. He expands the conversation and leads the audience into the pathos and reality of the untidiness of life and the meaning of specific events. This work, like many creative works by queer Indigenous peoples, where the movement is beyond being a marker of queerness (or of Indigeneity), allows an expansive view into the complexity of the rest of our lives.

Deborah Cheetham (Yorta Yorta) is this continent's most prominent First Nations' composer, singer and producer of opera. In her first major work, White Baptist Abba Fan, Cheetham explored how as the only Aboriginal person in her adoptive family, as a fan of opera, and as a lesbian growing up in an otherwise heteronormative, white, religious household she was simultaneously othered (Cheetham, 2018, p. 51). When she went on to create the first Indigenous opera, Pecan Summer, and the first Indigenous opera company, Short Black Opera, her queerness may not have appeared centred, but she argues her sexuality, as a part of her whole, informs the complexity of her work, her existence, and her resistance. That resistance manifests as a performer within a conservative field, through her refusal to perform the Australian National Anthem, is informed by all aspects of her resistance (Cheetham, 2018, p. 51).

While Oliver and Cheetham explore different terrain, they both tell a story of identity and belonging, through a lens of queer affect and resistance to the colonial project of forced identity. These are only two stories among thousands of creative representations from queer First Nations' people: luminaries, too many to list, like actor/playwright Uncle Jack Charles, theatre director Liza-Mare Syron, actor and writer Uncle Noel Tovey, singer Lou Bennett, performance poet Romaine Morton, novelist Melissa Lucashenko, visual artist Peter Waples-Crowe, writer Maddee Clarke, poet Ellen van Neerven, artist Todd Fernando, cabaret performer Ben Graetz, curators Genevieve Grieves and Myles RussellCook, and actor and producer Jacob Boehme. And even that list is inaccurate, as many of them work across far more than the ascribed creative practice area. Outside of the more established names, there is an emerging number of queer First Nations' peoples who are exploring their own complexities of who they are and who they may be. In mapping the increasing numbers, a compre- 
hensive list of LGBTIQ+ Indigenous creatives will reflect the sheer volume and complexity of work being created across this continent. Rather than reducing us to our Indigeneity or our queerness, by noting them in a strategic and gathered way, it aims to serve as a testament to their persistence, contribution, and resistance.

\section{Conclusions: Saving Lives}

The overarching program of "Saving Lives" aims to challenge symbolic annihilation by locating and centring our presence as a challenge to colonial erasures. Recalling our contributions responds to two central ideas: The first reminds us that representation and a sense of belonging is central to us as First Nations Peoples, as we work toward challenging the highest levels of youth suicide in the world (Bonson, 2016). Secondly, it recognises that 'saving' can challenge the ways in which we have been erased from the colonial record and even the ways in which we have been written in. As Lynette Russell points out, where there is truth in unreliability it is less about confabulation and more a result of the inconsistencies of record keeping in the colonial project of managing First Nations' Peoples (Russell, 2005, p. 164). We have the receipts, lets show them.

In research work conducted by Indigenous researchers about our Communities, there is often a story that sparks an initial kernel of interest. In a previous large study that I completed on representation in museums (O'Sullivan, 2019), it became apparent that there was little recognition of the influence of First Nations queer contributions. Like many queer Indigenous people my age, this lack of representation was born decades ago. At 55 , I can recall that the first queer person I saw represented was white, and all representations of Black people across the first few decades of my life were cisgender and straight. For me, cisgender, white characters in any story demonstrated an ability to move through the landscape with no identity questions asked of them. I saw them as baggage free, representing a blank slate on which I could write a story of hope and dreams, though as a transgender Black kid, never one I could realise. For decades, the civil rights activist Marian Wright Edelman has proclaimed that "you can't be what you can't see" (Young, 2018, p. 992), and my own story exposes that we have to challenge our own colonial mindset. On this continent, Alison Whittaker posits that the colonial structures will never deliver that sense of self, but proposes that we take control of the story of who we are as Indigenous queers (Whittaker, 2015, p. 227). Through this work, we can provide a level of visibility using our own, increasing and expanding constructions of diversity and complexity. While we must better understand the effect that queer visibility has on the wellbeing of Indigenous LGBTIQ+ people, we also must hold space for young people to create their own, complex futures.

\section{Acknowledgments}

I acknowledge that as a Wiradjuri person, I work on the unceded Dharug Ngurra. I pay my respects to ancestors, Elders and all within theirs and the other Communities written about in this article. I also acknowledge the creative effort of queer First Nations peoples in creating sites of knowing and being, as well as the efforts of academics and writers who are cited in the article, most of whom are First Nations peoples or people of colour.

\section{Conflict of Interests}

The author declares no conflict of interests.

\section{References}

Behrendt, L. (2021). Stories and words, advocacy and social justice: Finding voice for Aboriginal women in Australia. Australian Feminist Law Journal. Advance online publication. https://doi.org/10.1080/ 13200968.2020.1837538

Bonson, D. (2016). IndigenousX: Indigenous suicide, sexuality and gender diverse populations. IndigenousX. Retrieved from http://indigenousx.com.au/ indigenous-suicide-sexuality-and-gender-diversepopulations/\#.Vz6NNbTmTqs

Cheetham, D. (2018). So much still pending. In A. Heiss (Ed.), Growing up Aboriginal in Australia (pp. 47-51). Melbourne: Black Inc.

McLaughlin, B., \& Rodriguez, N. S. (2017). Identifying with a stereotype: The divergent effects of exposure to homosexual television characters. Journal of Homosexuality, 64(9), 1196-1213.

O'Sullivan, S. (2019). A lived experience of Aboriginal knowledges and perspectives: How cultural wisdom saved my life. In J. Higgs (Ed), Practice wisdom: Values and interpretations (pp. 107-112). Leiden: Sense-Brill.

Peruta, A., \& Powers, J. (2017). Look who's talking to our kids: Representations of race and gender in TV commercials on Nickelodeon. International Journal of Communication, 11(16), 1133-1148.

Russell, L. (2005). Indigenous knowledge and archives: Accessing hidden history and understandings. Australian Academic \& Research Libraries, 36(2), 161-171.

Watego, C. (2021). From Blackness-The genius and generosity of Steven Oliver. Indigenous $X$. Retrieved from https://indigenousx.com.au/from-blacknessthe-genius-and-generosity-of-steven-oliver

Whittaker, A. (2015). The border made of mirrors. In D. Hodge (Ed.), Colouring the rainbow: Blak queer and trans perspectives, life stories and essays by First Nations People of Australia (pp. 223-237). Adelaide: Wakefield Press.

Wilson, A. (2008). N'tacinowin inna nah': Our coming in stories. Canadian Woman Studies, 26(3), 193-199. 
Yan, H. Y. (2019). "The rippled perceptions": The effects of LGBT-inclusive tv on own attitudes and perceived attitudes of peers toward lesbians and gays. Journalism \& Mass Communication Quarterly, 96(3),
$848-871$.

Young, T. (2018). Invisibility and power in the digital age: Issues for feminist and queer narratology. Textual Practice, 32(6), 991-1006.

\section{About the Author}

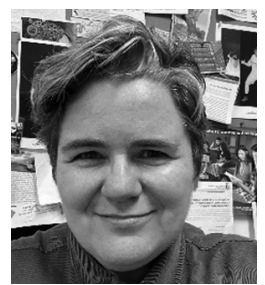

Sandy O'Sullivan is a Wiradjuri (Aboriginal), trans/non-binary Professor of Indigenous Studies at Macquarie University. Sandy works across museum studies, gender and queer studies, and across First Nations' body-resistance that challenges the colonial project. They recently completed a 470-museum study that explored the representation and engagement of First Nations' Peoples across museums and "Keeping Places" and continue to work in the University of Winnipeg's Museum Queeries collective. Sandy was recently awarded a million dollar 4-year Australian Research Council Future Fellowship for their project "Saving Lives: Mapping the Influence of Indigenous LGBTIQ+ Creative Artists." 